\title{
From STEM to STEAM: An Enactive and Ecological Continuum
}

\author{
Ronnie Videla ${ }^{1,2 *}$, Claudio Aguayo ${ }^{3}$ and Tomas Veloz ${ }^{4,5,6}$ \\ ${ }^{1}$ Escuela de Educación Diferencial, Facultad de Educación, Universidad Santo Tomás, La Serena, Chile, ${ }^{2}$ Departamento de \\ Educación, Facultad de Humanidades, Universidad de La Serena, La Serena, Chile, ${ }^{3}$ AppLab, Te Ara Poutama, Faculty of Māori \\ and Indigenous Development, Auckland University of Technology, Auckland, New Zealand, ${ }^{4}$ Foundation for the Interdisciplinary \\ Development of Science, Technology and Arts, Santiago, Chile, ${ }^{5}$ Centre Leo Apostel for Interdisciplinary Studies, Vrije Universiteit \\ Brussel, Brussels, Belgium, 'Departamento Ciencias Biológicas, Facultad Ciencias de La Vida, Universidad Andrés Bello, \\ Santiago, Chile
}

\section{OPEN ACCESS}

Edited by: Nathan Berger,

Western Sydney University, Australia

Reviewed by:

Allen Leung,

Hong Kong Baptist University, SAR

China

Kathryn Holmes,

Western Sydney University, Australia

${ }^{*}$ Correspondence: Ronnie Videla rvidela@userena.cl

Specialty section: This article was submitted to

STEM Education,

a section of the journal

Frontiers in Education

Received: 14 May 2021 Accepted: 02 September 2021 Published: 24 September 2021

Citation:

Videla R, Aguayo C and Veloz T (2021) From STEM to STEAM: An Enactive and Ecological Continuum.

Front. Educ. 6:709560. doi: 10.3389/feduc.2021.709560
STEM and STEAM education promotes the integration between science, technology, engineering, mathematics, and the arts. The latter aims at favoring deep and collaborative learning on students, through curricular integration in $\mathrm{K}-12$ science education. The enactive and ecological psychology approach to education puts attention on the role of the teacher, learning context and socio-cultural environment in shaping lived learning experiences. The approach describes education as a process of embodied cognitive assemblage of guided perception and action. The latter process depends on the interaction of learners with digital and/or analogue learning affordances existing within the socio-technological environment. This article proposes that the scope of an enactiveecological approach can be extended to the domain of learning science, technology, engineering, arts, and mathematics (STEAM), especially when it comes to understanding deep roots of the learning process. We first present an exhaustive literature review regarding the foundations of both the enactive and the ecological learning theories, along with their differences and key similarities. We then describe the fundamentals and latest research advances of an integrated STEAM pedagogy, followed by the notion of mixed reality (XR) as an emerging educational technology approach, offering an understanding of its current foundations and general disposition on how to understand digital immersion from ecological psychology. Next, we propose a systems theoretical approach to integrate the enactive-ecological approach in STEAM pedagogy, framed in the Santiago school of cognition attending to the interactive dynamics occurring between learners and their interaction with learning affordances existing within their educational medium, establishing that sensorimotor contingencies and attentional anchors are important to restrict sensory variety and stabilize learning concepts. Finally, we consider two empirical studies, one from Chile and the other from New Zealand, in which we demonstrate how the enactive-ecological approach built upon a systems theory perspective can contribute to understanding the roots of STEAM learning and inform its learning design.

Keywords: enactivism, ecological psychology, STEM/STEAM, mixed reality, science education, Santiago school of cognition 


\section{INTRODUCTION}

In 2012, the United States National Research Council proposed STEM (Science, Technology, Engineering and Mathematics) and STEAM (Science, Technology, Engineering, Arts and Mathematics) as a new form of teaching K-12 science education, seeking to promote curricular integration between science, technology, engineering, mathematics and the arts favoring deep and collaborative learning on students (Pellegrino and Hilton, 2012; Siekmann and Korbel, 2016; Miller et al., 2017). The need for a STEM/STEAM education, as proposed by the National Research Council, emphasizes that a strong foundation embedded in science skills is critical to meeting the technological challenges of post-industrial society. Frey and Osborne (2013) published a study on the 702 occupations listed by the United States Department of Labor, estimating that $47 \%$ of occupations have a high risk of disappearing in the next $10-20$ years as a product of computerization and automation of functions. From this study, a need to implement educational programs based on the development of perception and manipulation skills, creative intelligence, and social intelligence was also reported.

The evidence on STEM/STEAM reflects a body of research that intends to contribute from different dimensions to this field. With the aim of promoting integrated STEAM teaching, Liao (2016) proposed the creation of original stories using an online 3D modeling program, through TinkerCAD, in which students created $3 \mathrm{D}$ characters that they $3 \mathrm{D}$ printed to illustrate their books. The students created the interactive skins using Makey Makey and Scratch that allowed them to learn about scientific concepts underlying electronic circuits and electricity, as well as math skills for programming. To analyze the skillful progress in the manufacture of STEM artifacts, Hadani and Rood (2018) carried out various STEM experiences to observe how sensorimotor involvement contributes to the understanding of scientific content. Along the same lines, Weisberg and Newcomber (2017) explored the use of alternative sensorimotor exploration strategies that allowed students to connect scientific concepts they use when manipulating techno-scientific artifacts with the world of experience.

From a radical enactive cognitive approach (REC), Hutto et al. (2015) analyzed how the research design based on perceptionaction through the Mathematical Image Trainer for Proportion (MIT-P), favors effective motor control of perception action for the understanding of the mathematical concept of proportionality. These researchers proposed attentional anchors as a mechanism that channels attention during agentmedium couplings, as enabling restrictions for action (Hutto and Sánchez-García, 2014). In addition to this, Abrahamson et al. (2020) carried out an exhaustive review on different research approaches based on perception and action design, which would be very useful for STEM design. The researchers suggest that being informed about the research on how we learn to move in new ways could help us better design, measure, and theorize the performance of physical movements that underpin STEM learning, particularly the enactive and ecological approaches.
Even though the studies framed in the enactive and ecological approaches of Hutto et al. (2015) and Abrahamson et al. (2020) provide solid evidence about embodied design research and the sensorimotor dynamics that is at the base of learning in the context of STEM, we consider it necessary to report some untreated and highly relevant aspects within the framework of a unified enactive-ecological approach for a STEAM pedagogy. In particular, we consider certain knowledge gaps that are recognized in the empirical evidence and that would be of great use to researchers in the STEM/STEAM field and educational organizations wishing to incorporate these methodologies. Below we list these knowledge gaps and their associated knowledge backgrounds:

1) Lack of research on STEAM framed from an enactiveecological approach.

2) Technical foundations on principles of integrated teaching and learning in STEM/STEAM contexts, inside and outside of the classroom.

3) Incorporation of mixed reality (XR) as an educational technology approach within the STEAM framework from an enactive-ecological approach.

4) Unified enactive-ecological model from dynamic systems theory that allows understanding how students reconfigure their perception of effective action opportunities in digital and/or analog STEAM environments.

To justify point 1 ), we ascribe to the proposals of Abrahamson et al. (2020) on the need for enactive (Varela et al., 1991) and ecological (Gibson, 1979) approaches for the design of educational environments based on perception and action, since current approaches to cognition obviate the importance of cultural artifacts and the body as sources of knowledge. The enactive and ecological approaches provide new ways of understanding the role of sensorimotor activity in the development of learning experiences, mediated by the action of perception of and adaptation to the environment. Since STEM/ STEAM requires the construction of artifacts through an exploration mediated by digital and/or non-digital tools, the enactive and ecological approaches allow us to perceive certain things in certain ways by intuiting and apprehending them through the action of perception. To the extent where an organism resonates with available information, it is capable of directly perceiving the benefits, since what the organism perceives is the value of its current relationship with the environment through the processing of such information (Heft, 2007).

Regarding point 2), we adhere to the evidence presented by Pellegrino and Hilton (2012) who argue that the division of disciplinary knowledge leads to superficial learning on students who cannot transfer their learning to different contexts of knowledge, and therefore, are infertile to the potential resolution of complex problems. Integrating knowledge domains in teaching and learning practice through STEM/ STEAM pedagogy enables transferring learning between different levels and disciplines of knowledge, hence facilitating interconnected, deeper, and meaningful learning processes 
(English and Gainsburg, 2016), as well as collaborative and placebased learning (Penetito, 2009).

In relation to point 3 ), today there is increasing evidence on the benefits of mobile learning (learning with mobile devices such as smartphones and tablets) and new immersive learning technologies, such as augmented reality (AR), virtual reality (VR), and mixed reality (XR), across educational sectors (Aguayo et al., 2017; Lindsay, 2015). Educational technology literature provides encouraging accounts on how digital learning affordances (possibilities offered by digital technology) can not only incorporate and exploit STEM/ STEAM pedagogy (Boy, 2013; Jowsey and Aguayo, 2017), but also how embracing an enactive and ecological approach in designing mobile learning and XR learning experiences can facilitate a continuum of tangible authentic, hands-on, and self-determined (i.e. heutagogy) (Hase and Kenyon, 2013) learning experiences and affordances operating as an expansive learning ecosystem (Aguayo, 2020; Aguayo et al., 2020a).

Regarding point 4), we embrace the epistemological view of the Santiago school of cognition, coming from systems biology and founded on the concept of autopoiesis, where the process of intelligent cognition on a living organism is seen to occur as a result of the process of adaptation to its medium in any given living system (Hallowell, 2009; Maturana and Varela, 1980). Yet it also establishes that human experience and cognition are unique to every individual and context (Thompson, 2007). In this view, we propose a theoretical model as a proof of concept in STEAM, which integrates recent theory updates on the sensorimotor engagement that is at the base of the learning experience. In particular, we refer to the development of attentional anchors (Hutto and Myin, 2013), which consists of sensory restrictions that contribute to conceptual stabilization during the action of learners; and to the theory of sensorimotor contingencies that is based on the dynamic equilibrium of the flow of actions while the learner progressively engages in different situations (Buhrmann et al., 2013). We argue that a deep understanding of the STEM/ STEAM learning experience with attentional anchors requires sensorimotor contingencies that complement the explanation of sensorimotor dynamic equilibrium. For this, we propose from two case studies carried out in Chile (STEM) and New Zealand (STEAM), an application of our model that lays the foundations of a dynamic system that incorporates the progression of sensory restrictions that emerge from the structural coupling between learners and digital and non-digital STEM/STEAM environments.

Considering the above, our objective here is to offer a proof of concept on how an unified enactive-ecological approach within a dynamic systems theory lens based on the Santiago school can be usefully extended to the field of STEAM education, especially when it comes to understanding the deep roots of such sensorimotor learning in integrated teaching and learning contexts inside and outside of classroom. In making this case, we first present both the enactive and ecological approaches, with attention to the elementary foundations of each theory, their differences and similarities with ways of application to the STEAM field. This is followed by a section presenting the underlying considerations of an integrated STEAM pedagogy, where we describe the foundations and principles that govern the integration of curricula in educational contexts inside and outside of the classroom. Then a section on digital technology in education with attention to mixed reality (XR) as an emerging educational approach in the use of new and emerging immersive technologies in education STEAM. Drawing on these three main areas, i.e. the enactive and ecological approach, integrated STEAM pedagogy, and mixed reality in education as an expansive learning niche, we propose a unified enactive-ecological model underpinned by a dynamic systems theory logic derived from the Santiago school of cognition applicable in STEM/STEAM to understand embodied learning in context.

Finally, we use two STEM/STEAM cases of empirical evidence carried out respectively in Chile and New Zealand to demonstrate how our unified enactive-ecological model addresses each one of the three main areas presented above as proof of concept. We further outline a set of recommendations that lead to an expansive, place-based STEM/STEAM pedagogy that uses tangible analog and/or digital tools and deliverables from and within an enactive and ecological approach to science education across all educational sectors.

\section{LITERATURE REVIEW}

\section{Enactive Approach}

The appearance of the book The Embodied Mind by Varela et al. (1991) revolutionized current cognitive science, managing to articulate bodily phenomenological aspects from the work of Merleau-Ponty (2012) and the neuroscientific evidence of dynamic systems (Kelso and Fuchs, 2016). This allowed the introduction of the idea of continuity between perception, cognition, and action through the enactive approach. The advent of enactivism is opposed to internalist, computational, and representationalist foundations that reduce cognition to information processing at the head of objective stimuli (Varela, 1990). On the contrary, enactivism rejects the idea of an objective world that is surrendered, but rather, it is something that emerges as it moves (Varela, 1999). Hence, the metaphorical idea considers learning as tracing a path when walking (SotoAndrade, 2014).

This has roots in the foundations of the biology of knowledge coming from the Santiago school of cognition, in which living beings are considered adaptive, autonomous, and self-conserving agents that actively strive to maintain their own stability and structural integrity as a result of their history of coupling with the environment (Maturana and Varela, 1980). From enactivism, every human being is considered a cognitive system of selfreferential agents that define its own systemic identity and represents its own inherently significant environments, through adaptive processes of creation of meaning that emerge from the action of perception (Froese and Di Paolo, 2011). This approach is framed from a circular epistemology, in which the brain, the body, and the world are part of an entangled relational 
network of processes in which both the neural, non-neuronal, and nonbiological elements can play strong causal and constitutive functions in the action and perception (Di Paolo et al., 2017). The fundamental principles of enactivism are: "1) perception consists of perceptually guided action and 2) cognitive structures emerge from recurring sensorimotor patterns that allow action to be perceptually guided" (Varela et al., 1991, p. 172). The importance of enactivism for STEM/STEAM education lies in the fact that teachers, schools, and learning tools and affordances are the cultural collective in charge of generating educational environments and contexts capable of stimulating the natural perceptual capacity of students to reconfigure new ways of effective participation in the trans-disciplinary conceptual practice from their own experiences and vice versa.

\section{Ecological Psychology Approach}

The ecological psychology of Gibson (1979) proposes that cognition is promulgated, shaped, and structured by reciprocal interactions between the organism and the environment. This is due to the fact that the benefits of the organism and the environment are relational in nature, so that its epistemological core lies in the mutualism of reciprocal constitution that exists between the capacities formed by perceptual structures and the socio-material benefits. Heft (2007) argues that ecological psychology contributes to overcoming the nature and culture dichotomy, since an organism that perceives physical information from the environment does so in one that is already socially structured. Likewise, by being based on a mutualistic ontology, ecological psychology, like enactivism, abdicates the dichotomies of perception/action, organism/environment, subjective/objective, and mind/body that are at the base of the behavioral and cognitivist theoretical assumptions that ascribe to the poverty of the stimulus, the passivity of perception, and information processing (Heras-Escribano, 2016). As a methodological alternative to overcome the aforementioned dichotomies, ecological psychology establishes the concept of affordances that corresponds to human-animal behavior oriented by active exploration with significant opportunities for action.

An affordance can be understood as opportunities provided from the environment through information to act in a particular way. Information for Gibson is a specification relationship established by the legal covariation between energy patterns-optical, mechanical, and chemical-through time and/or space and objects or events in the environment (Szokolszky et al., 2019). From this perspective, humans like animals selectively respond to one information rather than another, in a way that is related to the dynamically changing needs of the individual according to the relevant possibilities in context (Rietveld et al., 2018). Affordances are attractive and bodily activation possibilities. Fuchs (2018) argues that the selective response capacity of the cognitive agent depends on relationships of circular organism-environment causality and not on cause-effect relationships. In this way, the importance of ecological psychology in the STEM/STEAM development framework lies in the design of educational environments that offer rich information to deploy techno-scientific skills that expand the ecological niche of each learner. This is generated by improving effective dynamic motor control with the digital and/or analog environment, a product of the emergence of attentional anchors that restrict sensory variety and improve adaptation.

\section{Integrating Science Education Through STEM/STEAM}

The need to cultivate generic skills, deep conceptual understandings and their interdisciplinary connections is paramount in the 21st Century skills development framework (English and Gainsburg, 2016). STEM/STEAM is presented as a field of educational development that requires integrated teaching to respond to real problems in each community (Becker and Park, 2011). However, the traditional curriculum in different parts of the world focuses on teaching discrete subject disciplines that truncate the implicit connections between the disciplines that lead to deep and ecological learning (Araya, 2012). Deep learning is knowledge transferable to various contexts, including thematic knowledge and procedural knowledge of how, why, and when to apply this knowledge to answer questions and solve real problems (Pellegrino and Hilton, 2012). Ecological learning emerges from the reconfiguration of sensorimotor experiences of exploration and manual control into skills of conceptual understanding transferable to diverse contexts (Abrahamson et al., 2020).

The interdisciplinary nature of STEM/STEAM is based on integrated teaching approaches that explore teaching and learning across different disciplines (Sanders, 2008). Honey et al. (2014) defines integration as "working in the context of complex phenomena or situations on tasks that require students to use knowledge and skills from multiple disciplines" (p. 52). Hurley (2001) has reported five types of curricular integration most used to teach science and mathematics in an interdisciplinary way: sequenced teaching, parallel teaching, partial teaching, total focus teaching, and enhanced teaching. Sequenced teaching consists of teaching one subject after another, whereas in the case of parallel teaching, both subjects are run simultaneously. Partial teaching consists of teaching partly together and partly as separate disciplines. In total focus teaching, subjects are taught together and in similar proportions. In the case of enhanced teaching, it constitutes a major teaching discipline.

The National Academy of the United States in their STEM integration in K-12 education report (2012), reveals that the use of integrated teaching applied to solving real problems helps students to transfer strategies, knowledge, and skills to new situations (Kelley and Knowles, 2016). Wynn and Harris (2012) argue that the connection between art and STEM enables cooperative learning between teachers that encourages students to learn through creative problem solving involving science, technology, engineering, mathematics, and the arts. To carry out the integrated teaching of STEM/STEAM in the curricula of schools that work with learning objectives, the ability of mathematical modeling becomes necessary to connect various disciplines (Araya, 2012). Mathematical modeling begins with a real-world problem, which is 
simplified, structured, and formalized into an ideal model (Maass, 2007). In this way, mathematical modeling has been recognized as fundamental in PISA (Programme for International Student Assessment) studies, where the positive impact on students' competence to apply mathematics to complex situations is regarded as "a powerful vehicle to transfer the characteristics of 21st Century problems to the classroom" (English and Gainsburg, 2016, p. 362). The importance of integrated teaching for STEM/STEAM educational environment designs is based on that of interdisciplinary practice that favors enactive and ecological learning, as well as didactic co-design. These new ways of teaching and learning are fundamental for the future of the post-industrialized society of the 21 st century.

\section{Educational Technology, Mixed Reality, and Digital STEM/STEAM Affordances}

The use and spread of digital technology, tools, and affordances in education has proved to enhance teaching and learning practice across sectors (Hennessy et al., 2019). Educational technology can provide integrated ecosystems of learning tools, instances, and affordances (Luckin, 2008) alongside a digital continuum of possible learning experiences (Liu et al., 2017), depending on the type of hardware, software, content and learning system, and on what skills, motivations, needs, and sociocultural baggage learners bring with them to the learning process (YamagataLynch, 2007). In the case of STEM/STEAM, educational technology can facilitate the augmentation and integration of critical STEM/STEAM concepts (Birt and Cowling, 2017), for example by making complex and abstract scientific concepts accessible to learners in meaningful ways (Jowsey and Aguayo, 2017).

Mobile learning, connected social learning, and the use of smart digital tools in STEM/STEAM education reconceptualized around user-centered and learner-centric educational design (Boy, 2013), and on what learners can do and create with digital affordances through self-determined and learnergenerated content and contexts, or heutagogy (Hase and Kenyon 2013; Luckin et al., 2010), brings about a new type of educational practice and pedagogy (Cook and Santos, 2016). This offers learners the possibility of authentic and self-determined learning experiences, enabled by the increasingly sophisticated affordances from rapidly advancing digital tools, demanding also rapidly adapting ad hoc pedagogies (Aguayo et al., 2017). However, what students can do with the new and emerging digital learning tools and possibilities depends not only on what the technology is, but also on the experience as a history of structural couplings with the environment (Dohn, 2009; Webb 2005). The skillful potential of each student is modulated by their ecological niche, since "the organism does not exist outside the ecological niche that makes it possible, since the organism and its niche are reciprocally constituted in an inseparable way" (Maturana and y Dávila, 2015 p 159).

Today, new immersive technologies such as real-time $3 \mathrm{D}$ data visualization, augmented reality (AR), and virtual reality (VR) can be conceived from a mixed reality (XR) approach (Milgram and Kishino, 1994), where digital immersion goes from the real environment (RE) end, where no digital immersion exists in the real world, all the way to the fully digitally immersive XR end, where digital immersion is at its full (Figure 1). XR environments as integrated, adaptable, and configurable learning ecosystems along a digital continuum offer unprecedented educational possibilities for free-choice, self-determined, authentic, and contextual learning experiences (Aguayo et al., 2020a; Speicher et al., 2019). XR as an emergent technology-enhanced learning approach in education invites us to conceptualize the learning context beyond hardware and software, by providing learners with modes of engaging with their environment through perception-action aesthetics, emotions, and haptics, while accounting for contexts (space), situations (time), and culture meaning-making (semantics) (Aguayo et al., 2020b; Mann et al., 2018).

$\mathrm{XR}$ can provide a continuum of analogue-to-digital hands-on and experiential affordances for place-based STEM/STEAM, by offering a range of sensorimotor learning "entry points" to the lived experience, as XR environments can be configured as a network of activities driven by digital affordances matching learners' motivations, characteristics, and needs, facilitated by adaptable and purposefully codesigned learning contexts (Aguayo, 2021; Maas and Hughes, 2020). Such configurations of digital STEM/STEAM affordances in the form of XR environments are suitable for an enactive and ecological approach to expansive STEM/STEAM pedagogy, given the ability to provide rich and varied learner-centered environments for learners to engage, couple, and enact with, following their own motivations, learning desires and needs.

\section{AN ENACTIVE AND ECOLOGICAL CONTINUUM}

In our model we propose a dynamic system approach following the epistemology of the Santiago school of cognition, for the integration of the enactive and ecological approach to cognition. We refer to the enactive approach, when we allude to the subpersonal dimension of the cognitive agents that are making their own worlds of meaning (Froese and Di Paolo, 2011). In the case of the ecological approach, we refer to the contextual and interpersonal dimension, in which cognitive agents perceive opportunities for action in sociomaterial environments that offer structured information (Heras-Escribano, 2019a). The unification of these approaches, seen as a continuum, allows us to understand the dynamic and embodied relationship of the cognitive agent and its environment. We are particularly interested in educational environments linked to STEM/ STEAM as a framework for specialized action (Rietveld et al., 2018).

We pay attention to emergent structural coupling in the form of transient patterns of perception-action loops that arise in STEM contexts in the classroom with analog technology and STEAM outside the classroom with mixed reality. We argue that the functional reorganization of actions to achieve learning objectives in STEM/STEAM educational environments requires consideration of the flow of sensorimotor actions that 


\section{Mixed Reality (XR) Immersion Continuum}

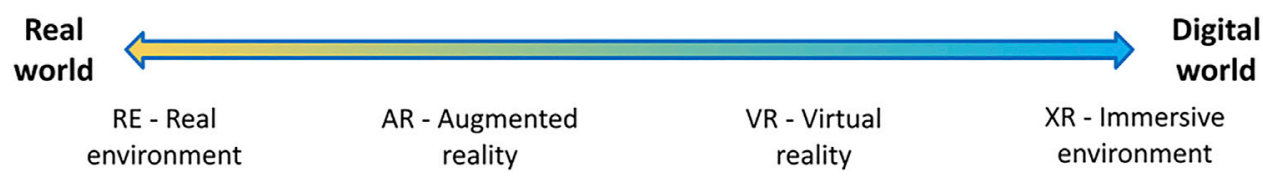

FIGURE 1 | The mixed reality (XR) immersive digital continuum (adapted from Milgram and Kishino, 1994).

give way to more sophisticated skills. These abilities are reconfigured within the framework of sensorimotor contingencies that allow experiencing the environment from greater to less sensory variety, depending on the degree of attunement of the learner and the physical characteristics of digital and analog artifacts (Buhrmann et al., 2013). To achieve a dynamic balance, we borrow the concept of attentional anchors that contribute to the effective motor control of conceptual stabilization. Sensorimotor contingencies maximize the structural and functional coupling from a progressive decrease in sensory variety, which through attention anchors allows capturing the emerging understanding product of self-organization that leads to conceptual stability (Philipona and O'Regan, 2010).

The model we propose highlights the skillful potential of learners in the framework of STEM/STEAM activities. These skills arise from the flow of sensorimotor contingencies and attentional anchors that lead to the effective deployment of the learner in the environment. In our systemic model we propose 5 skills that allow understanding learning in STEM/STEAM activities: 1) Exploration and manual control, 2) conceptual relationship, 3) strategic cognitive achievement, 4) conceptual understanding, and 5) enactive-ecological learning. From a systemic perspective, we offer within the framework of the design and implementation of STEM/STEAM learning activities, a proposal that integrates attentional anchors, sensorimotor contingencies and structural coupling to understand cognition and learning emergent in analog and virtual activities. Below we present the key theoretical concepts of our model: 1) structural coupling, 2) sensorimotor contingencies, and 3) attentional anchors. Then we explain each of the five abilities that we recognize as states that the organism takes as a product of the history of structural couplings in and with the environment. We propose in our model a relationship between skills and sensorimotor contingencies. That is, we assume that the greater the sensory variety, there is less of the type of structural coupling leading to the skills and, therefore, less effective sensorimotor contingencies to regulate dynamic control between the learner and STEM/STEAM activities. This dynamic flow of actions that translate into skills depends on attentional anchors that contribute to understanding and learning in digital and non-digital environments.

\section{Structural Coupling}

Learners tend to establish learning relationships as they are grasping the environment, through conceptual stabilization
(Abrahamson and Sánchez-García, 2016). For this, the environment plays a relevant role in the creation of a recurrent pattern of sensorimotor stabilization that is observed as the internal dynamics of the learner when structurally coupled. Structural coupling is defined as recurring and recursive interactions in which organisms transform their stories with the environment in a congruent way, through the conservation of their organization throughout all structural changes (Maturana and Pörksen, 2010). This occurs in all biological phenomena, since historical contingencies translated into sensorimotor activities generate plastic changes within the organism, which in turn modulate its capacities at a given moment (Rojas-Líbano and Parada, 2020). In this sense, cognition is a contingent phenomenon that is intertwined with the historical and natural evolution drift of the organism and the environment. In turn, it is phylogenetically and ontogenetically embedded in its ecological niche, so it can expand through activities that involve any type of movement. Structural coupling requires some environmental components to participate in the internal sensorimotor loop and become a transient constitutive mechanism (Parada, 2018). This mechanism can reach a greater sensorimotor complexity product of a history of previous couplings, from which more complex actions emerge contained in appropriate ecological niches (Rojas-Líbano and Parada, 2020). Product of the increase in sensorimotor complexity, the different dimensions constitute a flow of processes entangled on multiple scales, a continuous evolution whose structure is not exhausted by the cycles of metabolism or the environmental conditions (Di Paolo, 2020).

\section{Sensorimotor Contingencies}

Learners are always reconfiguring their actions by displaying various skills within the framework of educational settings inside and outside of the classroom, school, and beyond. This reorganization of actions occurs in the flow of transitory mechanisms that adopt general patterns that emerge during structural coupling (Roberts, 2009; Barandiaran and Egbert, 2013). The structure of rules that modulates the transitory mechanisms during the actions employed are called Sensorimotor Contingencies (SMC) (O'Regan and Noë, 2001). Buhrmann et al. (2013) distinguish four types of (SMC) that contribute to the understanding of the skillful progress of learning: 1) sensorimotor environment, 2) sensorimotor habitat, 3) sensorimotor coordination, and 4) sensorimotor strategies. In the case 1) sensorimotor environment, it is described as the instantaneous sensory consequences of 
movements in general of perceptual exploration, without considering sensory feedback, finding the learner dealing with an uncertain world in an open circuit of high sensory variety. The 2) sensorimotor habitat describes the relationship between sensory and motor activity with respect to the internal dynamics of the agent. In this sense, the apprentice navigates the environment from the identification of general regularities that lead to sensory restrictions typical of the evolution of internal states. The 3) sensorimotor coordination describes the identification of specific patterns functionally translated into performance objectives of the learner that are dynamically organized over time. Learners navigate in environments increasingly restricted by sensory variability and characterized by a significantly lower dimensionality than the sensorimotor habitat. In relation to the 4) sensorimotor strategies, these describe the learner-environment relationship according to normative or adaptive dimensions of high sensory restriction, modulated by action frames or possible results. Here, the learner configures a skillful knowledge that allows her or him to deploy effectively in the achievement of proposed objectives.

\section{Attentional Anchors}

Learners are continually faced with dynamic and changing environments that range from highest to lowest sensory restriction. In educational contexts, effective skillful deployment occurs through the flow of sensorimotor contingencies that occurs in the functional reorganization of actions oriented to certain events. To grasp the environment through conceptualization, learners stabilize their sensorimotor system through attentional anchors (Hutto and Myin, 2013; Hutto and Sánchez-García, 2014; Abrahamson, 2009). Considering that the dynamics of cognitive activity occurs embedded in the framework of embodied and situated interactions with environmental resources, the perspective of ecological dynamics conceptualizes learning as a complete system that tends toward a new dynamic equilibrium between the learner and the environment through the emergence of attentional anchors (Hutto et al., 2015). An attentional anchor is the focus of an actor's interaction with the environment that occurs as the agent's skill set grows through participation in a task (Ingold, 2000). In our terms, what one sees happening here is the growth of ontology through the extension of practice (Myin, 2000). Attention anchors channel attention during structural couplings as enabling constraints for action (Hutto and Sánchez-García, 2014). At the same time, the attentional anchors highlight the relevant possibilities of the environment through effective motor control of potential abilities. Attentional anchors interpolate between the internal dynamics of the learnerenvironment and facilitate the capture of emergent understanding and mediate reflection through a restriction of sensory variety during the flow of sensorimotor contingencies.

\section{A Unified Enactive-Ecological Model}

In our five proposed skills, i.e. 1) exploration and manual control, 2) conceptual relationship, 3) strategic cognitive achievement, 4) conceptual understanding, and 5) expansive enactive-ecological learning, the first skill "exploration and manual control" corresponds to the natural phylogenetic inclination by which cognitive agents spontaneously and naively display the first actions with objects. These skills involve perceiving a sensory variety, holding an object while walking or while others watch, interacting with a digital device, directing attention to multiple sources or recording a result, etc. The second skill "conceptual relationship" refers to the channeling of the course of actions, since the skills are oriented toward objectives necessary to achieve objective relationships and direct causalities, such as performing an action as a direct response to a stimulus in the environment, which is restricting the sensory variety.

The third skill "strategic cognitive achievement" corresponds to changes in actions that involve new ways of thinking with objects, which are induced by the cognitive discharge that occurs through a greater attentional commitment and extension of working memory. Framing (for example, heutagogy) and problem-solving skills are also highlighted, such as being able to describe the situation, solve a particular problem about the process to be carried out, or imagine alternative ways of carrying out the process. The fourth skill "conceptual understanding" involves the ability to adapt to the constraints and opportunities of the activity environment. Here scientific objects are treated as digital and non-digital physical objects through metaphorical and analog cognitive resources. Both resources are facilitated by perceptual and kinesthetic mapping, which entails to establish effective motor control for conceptual understanding.

Finally, the fifth skill "expansive enactive-ecological learning" relates to enactive and ecological skills through structural coupling (Gallagher, 2017; Maturana and Varela, 1980) and adaptation to available environmental STEM/ STEAM learning affordances (Mechsner, 2004), through processes of perception and guided action (Abrahamson et al., 2020). The expansive enactive-ecological learning is modulated by the different levels of normativity that occur in learning interactions inside and outside the classroom. It is oriented to the transfer of knowledge and its application in different contexts. Mathematical modeling is an example of expansive learning, since it incorporates the knowledge of science and technology through variables, to establish an abstraction of these in a simplified way.

In Figure 2 we represent our proposed unified enactiveecological continuum model for expansive STEM/STEAM pedagogy, denoting the emergent process of learning at the center as an enactive-ecological continuum determining the individual and collective learning and sensorimotor adaptation evolution. From the perspective of the Santiago school, this learning process occurring when learners engage with STEM/ STEAM affordances and learning activities through lived experiences is a process of structural coupling (Aguayo, 2020). The set of STEM/STEAM affordances contain the five proposed skills/actions-categories describing a STEM/STEAM activity. We see attentional anchors being part of and defining such a set of affordances, whereas sensorimotor contingencies exist in the socio-technological context of learners, whether inside and/or outside of the classroom, as depicted on the right side of the model. 


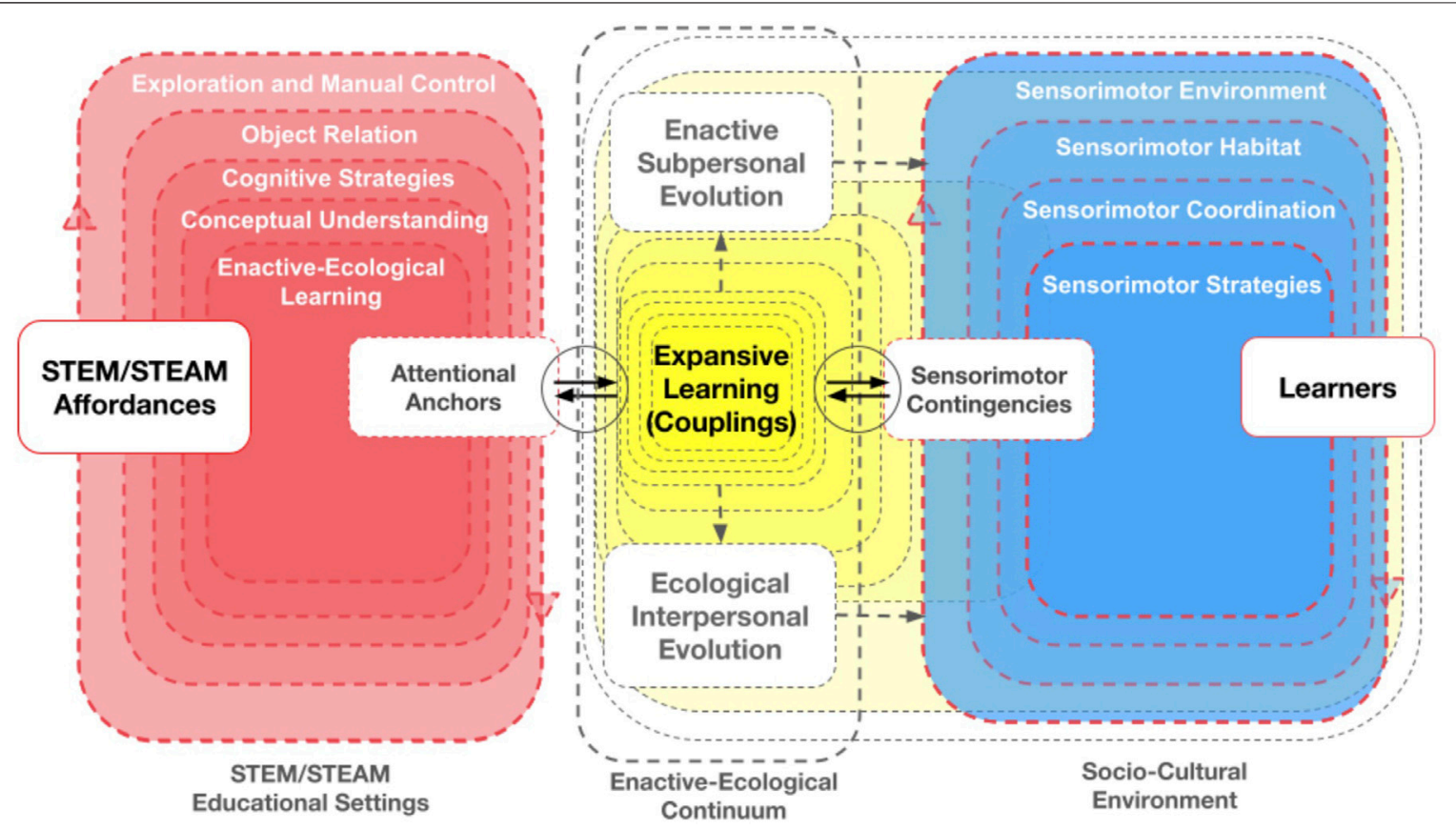

FIGURE 2 | The enactive-ecological continuum model for STEM/STEAM pedagogy, where the expansive learning process occurs as an ongoing set of structural couplings between the shared inter-action between learners (defined by the socio-cultural environment and historicity of individual enactive and collective ecological evolution) and STEM/STEAM affordances, through sensorimotor contingencies and attentional anchors.

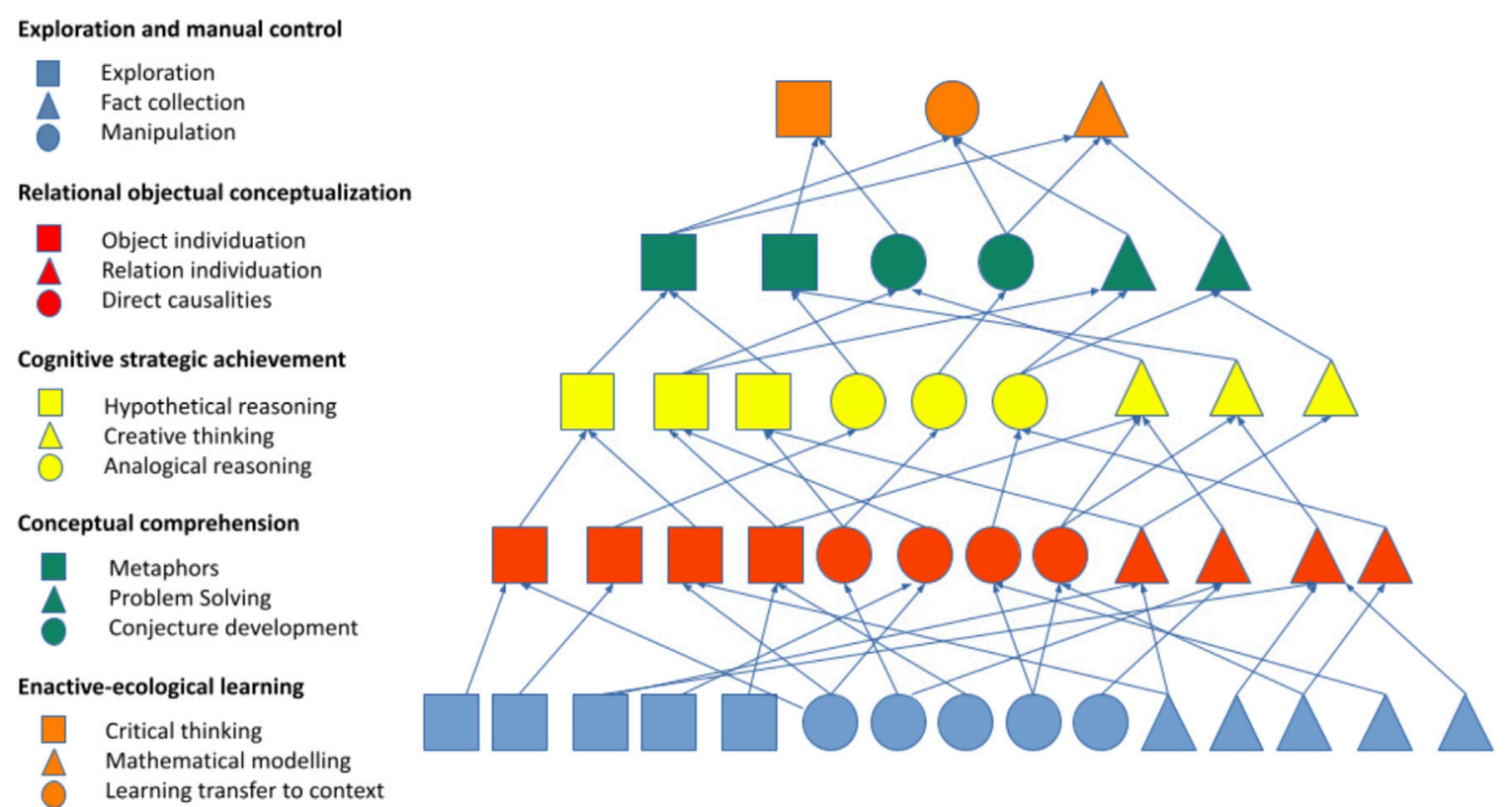

FIGURE 3 | Visualization of STEM/STEAM enactive-ecological pedagogy in the case of a formal and structured curriculum arranged from simple to more complex skills/activities. The figure represents the skillful progression in the STEM/STEAM education framework within the classroom. Here we can see that the organization of the learning experience begins from manual exploration to conceptual understanding and expansive learning. This is not a restrictive single street linear sequence, but rather a path made by walking within a specific STEM/STEAM area or category.

In practice, when designing a particular STEM/STEAM context, setting, and/or topic, first it is necessary to identify and define the different categories of STEM/STEAM activities into a conceptual network of skills/actions for such categories. For the sake of brevity, and to provide an example here, we can imagine a set of activities that corresponds to perform a particular 
Exploration and manual control

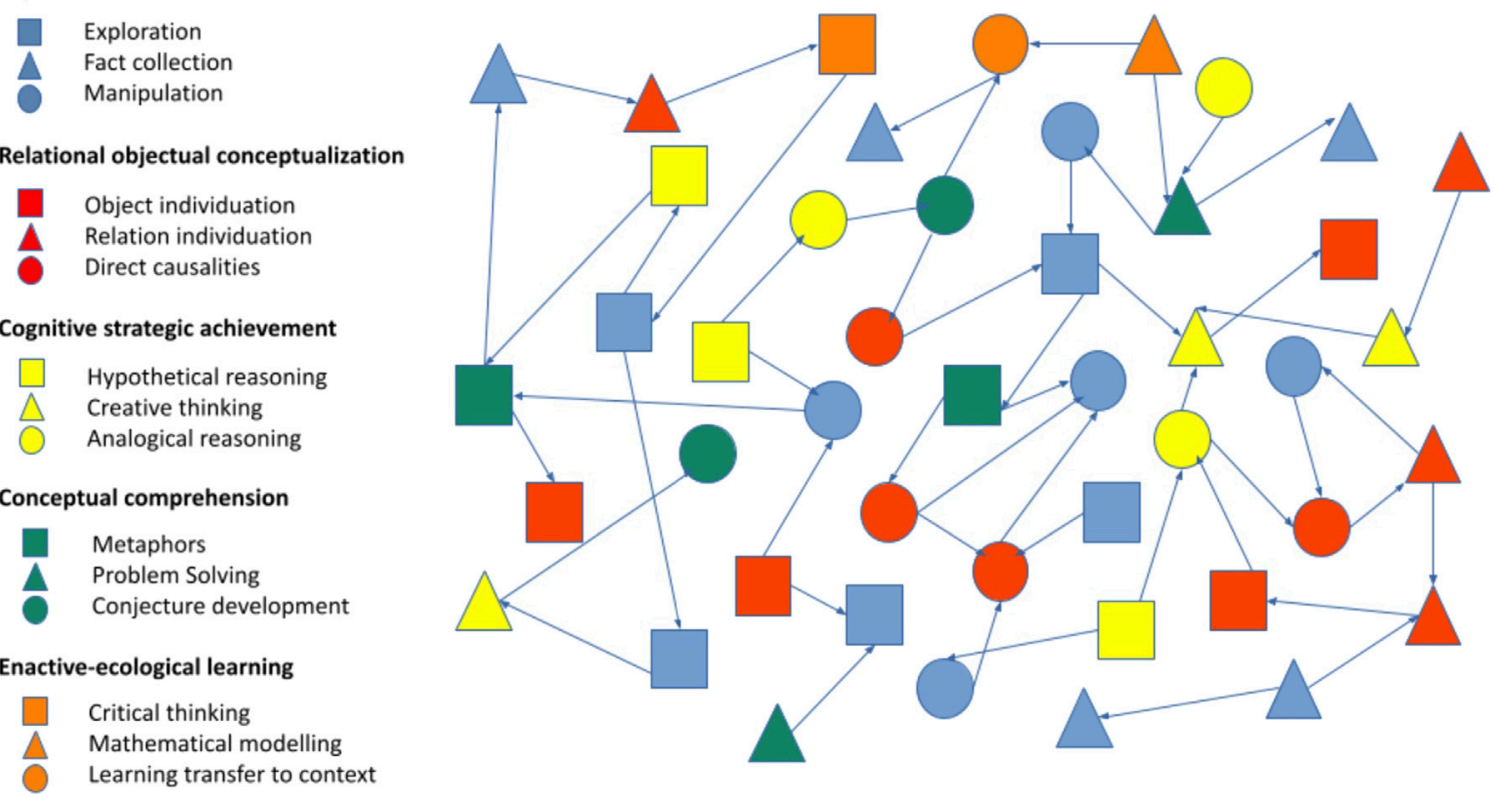

FIGURE 4 | Visual representation of a nonlinear global conceptual network of STEM/STEAM skills/actions learning activities, where different activities activate different parts of the global network, not necessarily restricted from simple to complex activities, as for example the fulfillment of complex activities can activate activity nodes leading to more simple and basic activities coming from more complex ones.

process that requires simple motor skills (like operating an analog or digital device), register the results of the process (by writing or on a digital device), and conclude something about the process from the results (in written or oral form) and/or reflecting on the process, in the case of free-choice learning settings such as museums or visitor centers.

Depending on the pedagogical structure of a STEM/STEAM learning experience, the conceptual network of skills/actions may be arranged, for example, in a hierarchical linear progression network where learners progress from simple to complex skills/ actions. The important aspect here is that complex skills require one or many simple skills for their activation. Thus, the conceptual network will connect various simpler skills to more complex skills, as shown in Figure 3. Clearly, the simpler skills that are connected to more complex skills might come from different STEM/STEAM categories. Indeed, the most complex skills will probably require basic and intermediate skills from all activity/skill categories. Yet some basic skills can also be activated from more complex skills coming from nodes from different categories, making the global network of activities a nonlinear network, as shown in Figure 4.

Thus, activities can be in principle planned for their serial application. In such a case, the learning process can strongly deviate from homogeneous learning because different learners might activate different parts of the network. Indeed, learners' predisposition, cultural-historical cognitive baggages, and enactive aspects that cannot be entirely foreseen during the happening of the activities, might end up in an unfair distribution of learning progress across learners, when in a formal education context (when compared to nonformal settings). For this reason, we propose that activities should be informed by a situated place-based pedagogy, decided on-the-go, and continuously evaluated by experts, teachers, and/or practitioners so group learning remains as homogeneous as possible. This is particularly interesting when considering digital affordances in mixed reality environments that can dynamically target and adapt to some of the learner's behavioral features (either actively or as a background process), and that additionally can be adapted and customized to local cultural and learning contexts, facilitating the activation of the desired nodes. In this latter case, groups of learners can collectively expand their activation of the conceptual network, reflecting on their learning.

\section{Empirical Context One: STEM Dynamometer in the Classroom}

The STEM dynamometer project in Primary formal education from Chile, reported by Videla et al. (2021) based on the enactive approaches of mathematical experience (Díaz-Rojas et al., 2021), and ecological approaches of learning experience (Abrahamson and Sánchez-García, 2016), assumed the educational problem of embodied design (Abrahamson, 2009) for addressing the learning of mathematical modeling and proportional reasoning. For this, a STEM design was proposed contemplating the construction of a dynamometer (technology) for estimating the portions in weights of each food (science) through mathematical modeling (mathematics).

In relation to our model, which is based on the reorganization of dynamic perception-action loops, in which learners are 


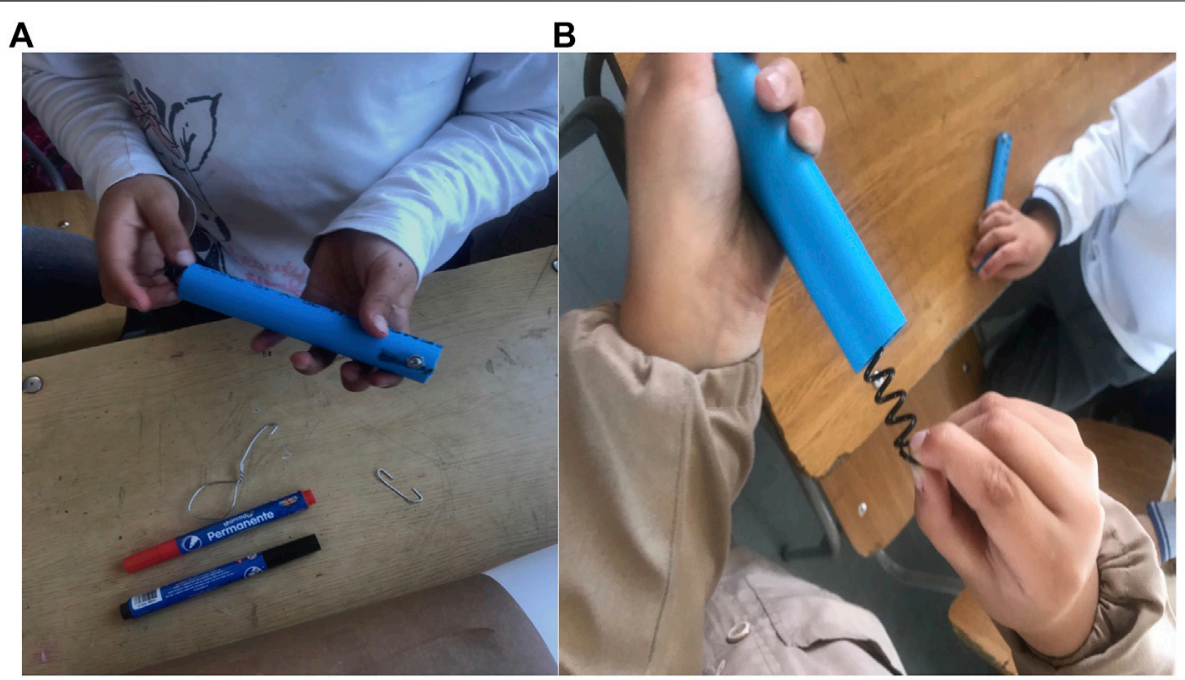

FIGURE 5 | (A) manual control and exploration; (B) object relations.

structurally coupled to physical objects, we describe changes in skillful actions as sensorimotor contingencies that regulate effective motor control of learners through attentional anchors that contribute to conceptual stabilization. In our model, we emphasize that STEM within the classroom organizes the learners' experience from exploration to understanding. This is to ensure that the learners can progressively engage with the artifacts and thus learn in action. We consider that the learning objectives of the study programs that participate in curricular integration contribute to orient pedagogical strategies that maximize the levels of normativity of the interaction between learners and artifacts. The sensory variety of the classroom is usually moderate, since the complexity of the STEM activity is centered on the artifacts of manipulation and exploration.

In Figure 5A concerning the state 1) of exploration skills and manual control that emerges in the contingency of "sensorimotor environment," it is possible to observe spontaneous movements of the learners with the materials without any instruction from the teacher. Here the perceptual flow of manipulating and seeing predominates in an environment of high sensory variety that does not allow grasping the meaning of physical objects, due to the fact that resonance with their internal dynamics does not prevail in the course of spontaneous actions (Buhrmann et al., 2013). The learner's movements lack sensory feedback from the physical objects corresponding to the dynamometer parts, so the sensorimotor environment becomes open and diffuse. This is because the attentional anchor that contributes to the restriction of sensory variety and facilitates the optimal coupling that facilitates effective motor control has not yet emerged.

On the image on the right side of Figure 5 alluding to state 2) such as relational object conceptualization, the learners manipulate and begin to ask about the usefulness of the dynamometer parts. The teacher encourages students to make conjectures and hypotheses about the usefulness of the parts of the dynamometer as they explore them sensually. Such is the case of a student who asks about the function of the spring through the execution of suspension movements triggered by the opening and closing of his index finger and thumb. The student has reconfigured his spontaneous movements into meaningful movements that allow him to connect with his previous experience. These movements occur within the framework of the "sensorimotor habitat" contingency, since the first levels of sensory restriction that appear arise from specific patterns of interactions with the environment. Here the repetitive actions emerge from the closure of the coupling cycle as a result of motor variations and sensory feedback. In the case of the learner who, by moving his fingers, emulates the suspension function of the spring, it can be established that his internal dynamics create sensory and motor restrictions that originate completely new behaviors as a result of a prolonged coupling (Buhrmann et al., 2013).

Following Figure 6A concerning state 3) of strategic cognitive achievement, the learners progressively begin to reconfigure their naive and intuitive explorations about the function of materials in explorations with scientific utility products of the specialization of perception and action. This is due to the appearance of the attentional anchor that interpolates between the internal dynamics of the learner and the environment translated into the pieces of the dynamometer, restricting the sensory variety. The learners' actions begin to be more specific and guided by perception, which allows them to grasp the environment through the assembly of the dynamometer parts. These actions emerge as sensorimotor coordination contingencies, since they functionally contribute to the performance or objectives of the learner. Sensorimotor coordination is based on transient patterns of dynamic coupling, the learners build the dynamometer and experience a significantly lower dimensionality of actions than the sensorimotor habitat as a whole (Buhrmann et al., 2013). This leads to selectively direct attention and therefore maximize concentration to reflect on the function of the dynamometer. 


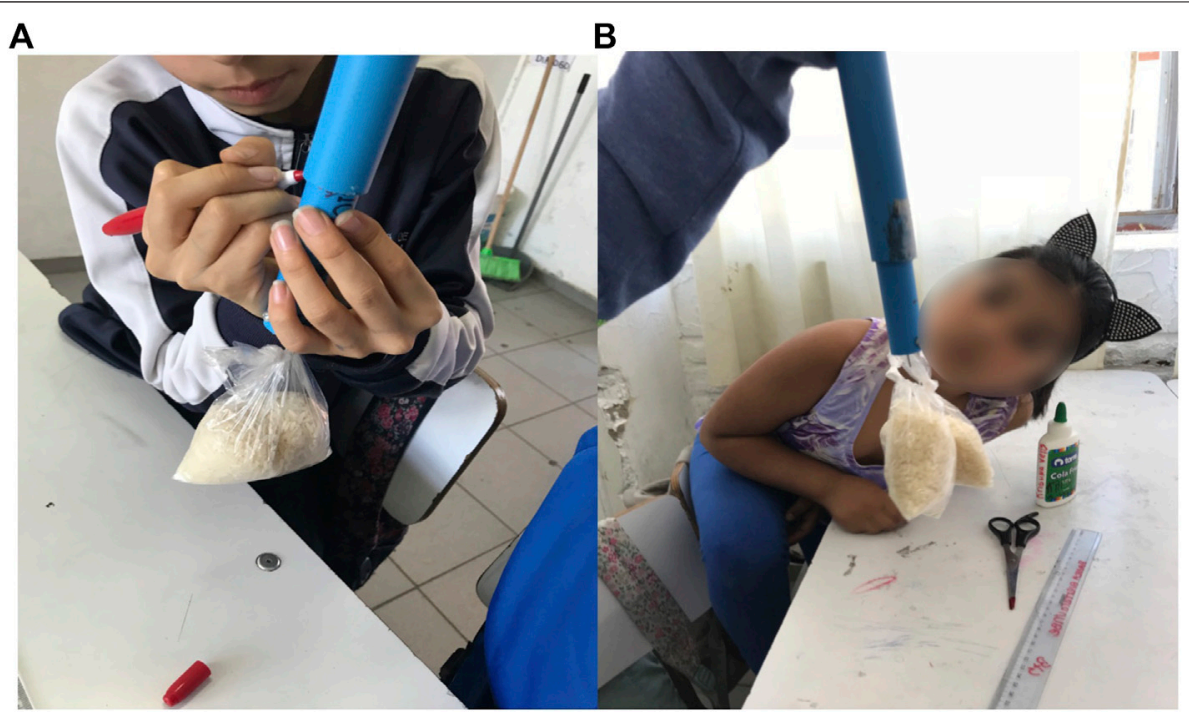

FIGURE 6 | (A) strategic cognitive achievement; (B) conceptual understanding.

Regarding the image on the right side of Figure 6 concerning state 4) conceptual understanding, the students place various portions of food in plastic bags. They carefully observe the variations in centimeters that represent the different weights of the loads. They continually pay attention to the different foods and take note of the changes. This occurs due to the function of attentional anchors that contributes to channeling attention during perception-action couplings, generating enabling restrictions for effective action (Hutto et al., 2015). When the teacher begins to ask the students to pay attention to the relationships between the variations of centimeters and the weight of the food, the actions of perception and manipulation are reconfigured in conceptual understanding of proportional reasoning. The learners observe "that when weighing $100 \mathrm{~g}$ the dynamometer reports $2 \mathrm{~cm}$." The teacher asks them, and if the weight increases to $400 \mathrm{~g}$, how much should the magnitude in centimeters of the dynamometer report. In these actions, the emergence of motor coordination patterns that learners use regularly and that are normatively organized according to levels of ability, efficiency, and stability is evidenced (Buhrmann et al., 2013). This type of contingency is called sensorimotor strategy, it describes how learners must reconfigure their actions to respond to a specific situation, as is the case of proportional reasoning.

In the case of state 5) expansive enactive-ecological learning, learners are able to establish through the simple rule of three the mathematical modeling of proportional reasoning. For this, they establish direct relationships of proportionality, by linking the variations in the weight of the food and the magnitudes in centimeters that the dynamometer throws up. The interesting thing about this STEM activity is that the learners ended up doing math, as they participated in technology and science. This reaffirms the skillful potential in the framework of disciplinary integration environments based on the action of perception.

\section{Empirical Context Two: STEAM Free-Choice Learning Using Mixed Reality (XR)}

In this case study reported by Eames and Aguayo (2020), the authors explored how mobile learning tools and affordances can be used and shaped to promote marine ecological literacy in education outside the classroom (EOTC); and how EOTC learning can be reinforced in the classroom post-visit. This research was informed by heutagogy, or self-determined learning, using digital tools and affordances following a mixed reality (XR) approach; and free-choice learning in an EOTC environment (Ministry of Education, 2016), i.e. a marine discovery center located at a marine reserve near Auckland, in New Zealand. The research team partnered up with a primary school teacher and her classroom (over a period of 2 years), and with two marine science educators, two marine scientists, and a mobile learning expert, setting up a community of practice (Wenger, 1999). This research took place between 2017 and 2019 (Eames and Aguayo, 2020, for details).

In relation to our model, we highlight that STEAM outside the classroom provides multiple ways of interacting that lead to skillful reorganization with low levels of normativity. We believe that the natural snorkeling environment combined with the marine discovery center expands affordances contributing to maximizing the resonance of STEAM activities with the learning experience (Ryan and Gallagher, 2020). The programmatic objectives of the curriculum in nonformal education contexts are transformed into enriched landscapes that favor cooperative learning and perceptual navigation. This leads to expansive learning characterized by the nonlinearity of 


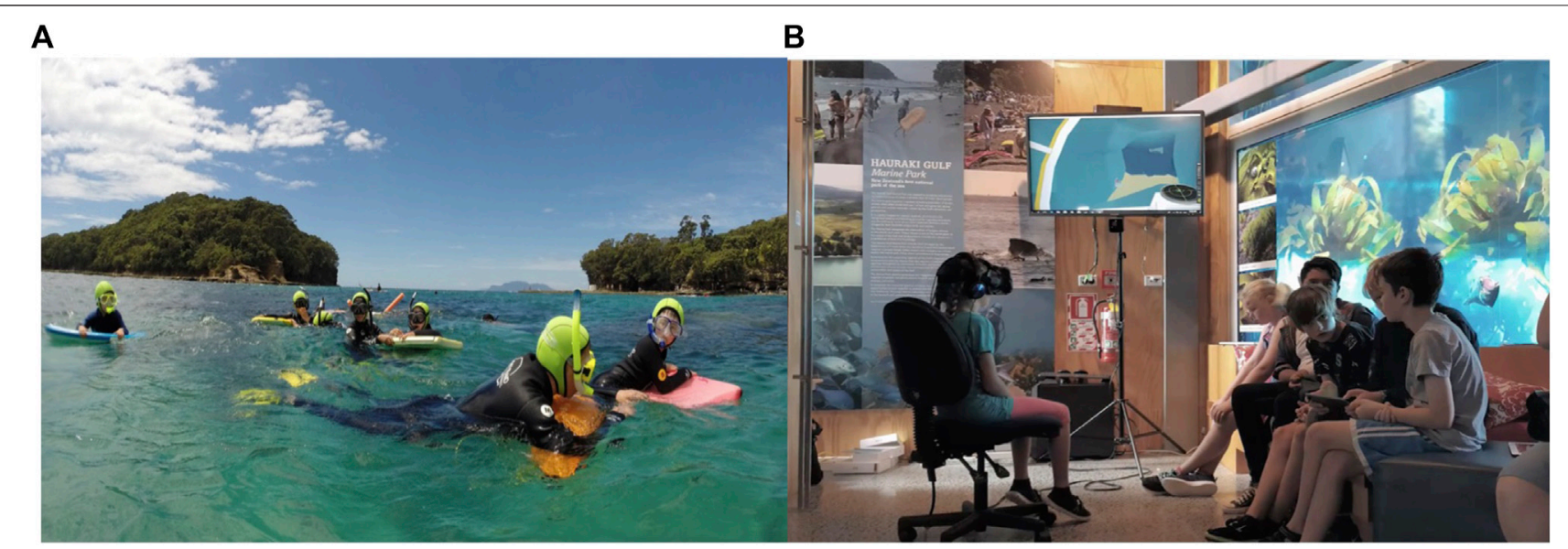

FIGURE 7 | (A) students experiencing the underwater world while taking part of a snorkel group tour; (B) Pipi's World VR experience using a high-end (HTC Vive) setup, where children interact with pipi the young snapper fish telling the story of her protected marine environment (source: Aguayo and Eames, 2018).

skillful progress, as depicted in the nonlinear network of STEM/ STEAM skills/actions learning activities example from Figure 4.

In this STEAM case the learning experience occurring in settings outside of school offers multiple possibilities for the learners' action, since changes in perception provide advantages for action and vice versa. This is because learners actively participate in different environments, following a mixed reality framework, reorganizing their experiences in a dynamic loop of exploration and maximization of permanent understanding. Learners experienced a snorkeling group tour in the marine reserve, complemented by a visit to the marine discovery center that included a series of analog to digital complementary learning activities, including augmented reality (AR) activations (about lobster migration, plastic, food web, and ocean acidification), 360 virtual reality (VR) videos of the marine reserved (aerial, land, and underwater) enabled by $\mathrm{QR}$ codes placed around the center, both viewed through the use of a specially purposed mobile application; and a high-end computergenerated interface VR experience (using an HTC Vive set up). Unlike the STEM case within the classroom that is programmatically oriented toward a progressive trajectory of sensorimotor flow and with higher levels of normativity, this STEAM case outside the classroom exhibits a recursive circular dynamic of expansion of perceptual learning, in which the systematic exploration of haptic-visual perception is transformed into indispensable patterns for conceptual stabilization.

Figure 7A illustrates learners participating in the experiential learning snorkeling activity in which they explore and navigate to learn about the underwater world and the different species present in this protected environment. Here learners are deployed in the open skillful flow of exploration and manual control that emerges from the tactile and haptic sensations constituted from the sensorimotor environment contingency. In this open sensorimotor flow in which the actions do not attend to the internal dynamics of the learners, the sensory variety is maximized, and the motor imbalance increases. Once the trainees coordinate their entire body movements during underwater deployment, the contingency of sensorimotor habitat emerges as a result of sensory feedback. At first the movements displayed are usually erratic and without specific objectives, beyond staying afloat and navigating such novel environment for most. Progressively engaged in the underwater environment, they deploy meaningful movements toward targets through coordinated action patterns.

Regarding Figure $\mathbf{7 B}$, learners are depicted in the marine museum collaboratively taking part of the virtual reality experience, complementing the knowledge experienced during the snorkeling experience. The skill that emerges in this activity is 2) relational object conceptualization, since learners establish relationships between the underwater ecosystem observed transiently while immersing themselves in the ocean, with the narrative they can experience at length with virtual reality. This again entails resorting to the ability of exploration and manual control, but from an immersive digital learning experience logic that recruits changes in perception and new possibilities for action. To the extent that the exploration environment is closed to a flow of visual perception, for example, in a certain space on the seabed where there are designated types of species, the actions carried out by the learners tend to reach a level of resistance that reverses the direction of movements in action patterns product of sensory feedback. This corresponds to the sensorimotor habitat contingency that highlights the dynamic structure of the learner.

In relation to Figure 8A, a learner can be seen manipulating a digital tablet while engaging with an app-based augmented reality (AR) experience, haptically perceiving the regularities of objects and shaping what he is learning. In this way, their learning is consolidated through a greater restriction of the sensory variety generated by the attentional anchors offered by the digital affordances in context interpolating between their dynamics of actions and the digital affordances offered by AR, that is, between the real experience of him, with virtual reality and with augmented reality. This cycle of interconnected concatenated 


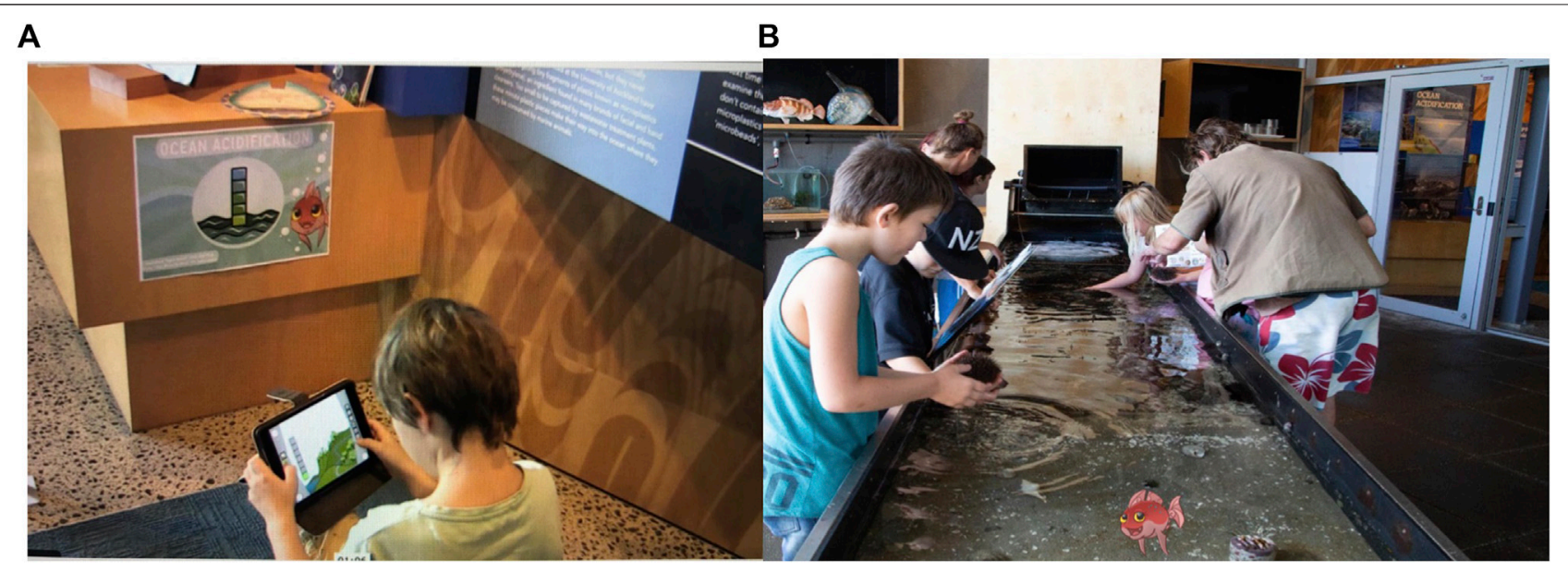

FIGURE 8 | (A) student learner engaging with an app-based augmented reality (AR) experience on ocean acidification and links to climate change; (B) touch tank activity engaging haptic and aesthetic experiences within the XR continuum (source: Aguayo and Eames, 2018).

actions is reflected in a rhythmic pattern that is oriented toward certain objectives given the contingency of sensorimotor coordination that highlights the selection of transitory mechanisms for the achievement of objectives. Product of this focus of attention and sensorimotor coordination emerges the ability of 3) strategic knowledge.

On the right-side image in Figure 8, the students are portrayed in the touch tank section of the marine discovery center where they can integrate in real time the visual-haptic exploration of real marine environments in a container and the use of, for example, the set of AR activities complementing this analog hands-on experience to maximize learning (Aguayo et al., 2020a). The activities that students carry out are modulated by effective motor control that contributes to conceptual stabilization. This is due in part to the attentional anchors that capture the emergent understanding during the flow of actions and the contingency of sensorimotor strategies that allows effective and efficient learning in normative frameworks that oscillate in tangled environments of real environment reality and digital immersion realities (i.e. therefore mixed reality). The dynamic balance of the learner and the real-virtual environment provides the necessary scaffolds for conceptual understanding integration.

Finally, 5) expansive enactive-ecological learning emerges in the continuous reorganization of exploration and comprehension skills, which, according to levels of entanglement between learners and virtual-real environments, maximize the possibilities of action and the effectiveness of learning within a coherent narrative on marine conservation. Once the sensorimotor strategies have adapted to the experiential becoming of the learners, they can make use of the concepts of marine conservation as a "skillful knowledge." Skillful knowledge consists of perception-modulated actions that are tuned to a specific situation and progressively refined according to its dispositions through dynamic balance. Likewise, new concepts can be expanded to other situations in which appropriate actions emerge on the basis of past experience and in accordance with objectives that resonate with the structures. These new concepts do not imply representations of knowledge, but a dynamic complex of images and sensations that tend toward metastable tuning. When the situation changes, sensorimotor contingencies and abilities are reconfigured according to the flow of structural couplings.

\section{DISCUSSION}

In the formal education STEM case conducted in Chile, and the free-choice learning (nonformal education) XR STEAM example case conducted in New Zealand, descriptions are provided regarding the process of learning within the framework of a dynamic systems theory model integrating enactive and ecological approaches considered as a continuum. We appeal to these empirical case descriptions as proof of concept to enrich our theoretical model. We consider relevant for the development of an expansive STEM/STEAM pedagogy to provide explanatory models contributing to understanding how students, when practicing with digital and non-digital tools, display more sophisticated skills according to the emergence of attentional anchors that restrict sensory variety within the framework of a flow of sensorimotor contingencies. We affirm that understanding the natural drift of structural couplings at the body level and with/through the use of artifacts leads to a pertinent theoretical framework that reveals the role of the body and artifacts in STEM and STEAM educational settings.

Unlike studies in this line, such as that of Hutto et al. (2015) in which a proof of concept of the Radical Enactive Cognition (REC) approach (Hutto and Myin, 2013) is exposed through the development of attentional anchors in STEM activities, we additionally propose the integration of sensorimotor contingencies (Buhrmann et al., 2013) and the ecological dimension of cognition in STEAM environments in the context of mixed reality (Aguayo et al., 2020a) as an emerging approach in educational technology (Aguayo, 2021), to broaden the understanding of the embodied learning experience in and 
out of school, i.e. in formal and nonformal settings. This gives greater ecological validity to the proposed theories, since they are generally carried out in controlled experimentation environments. We decided to incorporate sensorimotor contingencies to illustrate the skillful reorganization of actions as a function of sensory restrictions that emerge from information patterns that are attuned to the lived experience. What is relevant in our proposal is the flow of structural couplings of learners with STEM/STEAM artifacts, who from the detection of regularities, are reconfiguring new possible action scenarios that are possible by the niche of available affordances in the environment.

The regularities maximize the dynamic control of the learner with the environment, which contributes to the effectiveness of the skill and conceptual stabilization. In the STEM dynamometer case, the skillful progression of learners can be evidenced, going from greater to less sensory variety. From the descriptions presented, a flow of actions of coordination and selection of sensorimotor strategies that emerge from the sensory restriction generated by the attentional anchors is observed. Sensorimotor contingencies are fully in tune with the five skill states or levels that we propose: 1) exploration and manual control, 2) conceptual relationships, 3) strategic cognitive achievement, 4) conceptual understanding, and 5) expansive enactive-ecological learning. The same is possible to identify in the case of STEAM with mixed reality, where this sensorimotor flow depends on the skillful potential reciprocity of the learners and the digital affordances available through the coupling with real, haptic, digital, augmented, and virtual reality affordances along a mixed reality continuum offering several and varied entry points, i.e., attentional anchors, for non-lineal expansive learning to occur.

These analyses are in tune with recent embodied instrumentation of body-artifact functional system approaches by Shvarts et al. (2021) that state that the potentialities and bodily possibilities frame perception and action, which in turn reveal the influence of the environment on the organism and an influence of the organism on the environment. Another relevant aspect of our study consists of resuming the criticism that is made to the $4 \mathrm{E}$ of cognition (embodied, enactive, embedded, and extended) by not incorporating ecological psychology as a $5 \mathrm{E}$, on the grounds that its epistemic framework is based on controlled experiments that lack real organisms and lived experiences (Gonzalez-Grandón and Froese, 2018). In our study we incorporated the ecological approach to cognition with real students in natural contexts inside and outside the classroom. We demonstrate the dynamics of the skillful flow that emerges in the framework of sensorimotor contingencies and attentional anchors. Likewise, we propose a unified model between enactive and ecological approaches from systems theory and the Santiago school, which contributes to the post-cognitivist field of research that seeks to strengthen a unified approach to sub-personal and interpersonal agency (Heras-Escribano, 2019b; Ryan and Gallagher, 2020; Segundo-Ortin, 2021).

In our proof-of-concept study, we argue STEM and STEAM as educational environments in the form of ecological niches of techno-scientific expansion to the extent that the activities that are designed in an integrated manner resonate with the socio-cultural and socio-technological experiences of the learners. Techno-scientific expansion is generated from the resolution and/or confrontation of real and authentic problems, in which students manage to reconfigure naive motor skills into scientific notions with pedagogical and contextual utility. The cases presented show experiences of learning improvement from the embodiment of the experience, and were complemented with digital possibilities combined with practical and tangible haptic (embodied) experiences framed within a continuous approach of $\mathrm{XR}$ immersion. This offered an ecosystem of multiple "entry points" and interactive and situational facilities tailored to the diverse sociocultural and literacy backgrounds of learners (Aguayo et al., 2020a). Considering the suggestions of Abrahamson et al. (2020) on the new challenges in the STEM field, we incorporated STEAM and a theoretical model that unifies the enactive and ecological approaches from systems theory that enhances design-based research.

\section{CONCLUSION}

In this article, we have considered a proof of concept for a unified enactive-ecological model within the framework of systems theory underpinned by the epistemology of the Santiago school of cognition, which, if correct, shows that the model has real practical and empirical implications in STEM/STEAM pedagogy across educational settings. The proposed model integrates theoretical and empirical foundations from the research fields of embodied design and technology-enhanced learning. Part of this model is nourished by tests carried out in the educational fields of sports (Davids et al., 2013) and mathematics and STEM education (Hutto et al., 2015). If our results are correct and contribute to the understanding of the learning experience in digital and non-digital environments, we appeal to its potential extrapolation and contextual adaptation in different places that are interested in an expansive STEM/STEAM pedagogy.

\section{DATA AVAILABILITY STATEMENT}

The raw data supporting the conclusion of this article will be made available by the authors, without undue reservation.

\section{ETHICS STATEMENT}

The studies involving human participants were reviewed and approved by the Ethics Committees of the Universidad Santo Tomás and Auckland University of Technology. Written informed consent to participate in this study was provided by the participants' legal guardian/next of kin.

\section{AUTHOR CONTRIBUTIONS}

All authors listed have made a substantial, direct and intellectual contribution to the work, and approved it for publication. 


\section{REFERENCES}

Abrahamson, D., and Bakker, A. (2016). Making Sense of Movement in Embodied Design for Mathematics Learning. Cogn. Res. Princ Implic 1 (1), 33. doi:10.1186/ s41235-016-0034-3

Abrahamson, D. (2009). Embodied Design: Constructing Means for Constructing Meaning. Educ. Stud. Math. 70 (1), 27-47. doi:10.1007/s10649-008-91371Electronic supplementary material at http://edrl.berkeley.edu/publications/ journals/ESM/Abrahamson-ESM/.

Abrahamson, D., Nathan, M., Williams-Pierce, C., Walkington, C., Ottmar, E., Soto, H., et al. (2020). The Future of Embodied Design for Mathematics Teaching and Learning. Front. Educ. 5, 147. doi:10.3389/feduc.2020.00147

Abrahamson, D., and Sánchez-García, R. (2016). Learning Is Moving in New Ways: The Ecological Dynamics of Mathematics Education. J. Learn. Sci. 25 (2), 203-239. doi:10.1080/10508406.2016.1143370

Aguayo, C. (2016). "Activity Theory and Online Community Education for Sustainability," in Activity Theory in Education. Editors D. Gedera and P. J. Williams (Rotterdam: Sense Publishers), 139-151. doi:10.1007/978-946300-387-2_9

Aguayo, C., Cochrane, T., and Narayan, V. (2017). Key Themes in mobile Learning: Prospects for Learner-Generated Learning through AR and VR. Australas. J. Educ. Technol. 33 (6), 27-40. doi:10.14742/ajet.3671

Aguayo, C., Eames, C., and Cochrane, T. (2020a). A Framework for Mixed Reality Free-Choice, Self-Determined Learning. Res. Learn. Technol. 28, 2347. doi:10.25304/rlt.v28.2347

Aguayo, C., and Eames, C. (2018). Mixed Reality Learning in Marine Ecological Literacy Education. Paper Presented at the National Marine Educators Association Conference, 16-20 July 2018, Long Beach CA, USA: NMEA. Available at: https://www.researchgate.net/publication/353885513_Mixed_ Reality_learning_in_marine_ecological_literacy_education.

Aguayo, C., Ferrari, R., Moradi, P., Montiel, M., and Taheri, A. (2020b). "Embodiment in Digital Enaction: Considering the Role of Semantics in XR Design," in Poster presented at An Embodied Approach to the Study of Experience (EASE), 5-9 October, The Centro de Estudios Laboratorio de Fenomenología Corporal (Valparaiso, Chile: LAFEC). doi:10.6084/ m9.figshare.15097863

Aguayo, C. (2020). Interface Xperience. pjtel 2 (1), 54-55. doi:10.24135/ pjtel.v2i1.69

Aguayo, C. (2021). Mixed Reality (XR) Research and Practice. Pac. J. Technol. Enhanced Learn. 3 (1), 41-42. doi:10.24135/pjtel.v3i1.104

Amiel, T., and Reeves, T. C. (2008). Design-based Research and Educational Technology: Rethinking Technology and the Research Agenda. Educ. Technol. Soc. 11 (4), 29-40.

Araya, R. (2012). "Introducing Mathematical Modeling Skills in the Curriculum," in Mathemati- Cal Modeling Course in Mathematics Curriculum: Some Best Practices in APEC, Economies.

Barandiaran, X. E., and Egbert, M. D. (2013). Norm-establishing and NormFollowing in Autonomous agency. Artif. Life 91, 1-24. doi:10.1162/ ARTL_a_00094

Becker, K., and Park, K. (2011). Effects of Integrative Approaches Among Science, Technology, Engineering, and Mathematics (STEM) Subjects on Students' Learning: a Preliminary Meta-Analysis. J. STEM Educ. 12 (5/6), 23-37. doi:10.12691/education-2-10-4

Bellei, C., and Morewietz, L. (2016). "Strong Content, Weak Tools. Twenty-FirstCentury Competencies in the Chilean Educational Reform," in Teaching and Learning for the Twenty-First-Century: Educational Goals, Policies, and Curricula from Six Nations. Editors F. M. Reimers and C. Chung (Cambridge, MA: Harvard Education Press), 93-126.

Birt, J., and Cowling, M. (2017). Toward Future 'mixed Reality' Learning Spaces for STEAM Education. Int. J. Innovation Sci. Maths. Educ. 25 (4), 1. doi:10.14742/ ajet.3596

Blanchard, M., Gutierrez, K., Habig, B., Gupta, P., and Adams, J. (2020). "Informal STEM Program Learning," in Handbook of Research on STEM Education. Editors C. Johnson, M. Mohr-Schroeder, T. Moore, and L. English (Routledge: Taylor \& Francis), 138-151. doi:10.4324/ 9780429021381-14
Bonderup Dohn, N. (2009). Affordances Revisited: Articulating a Merleau-Pontian View. Comput. Supported Learn. 4 (2), 151-170. doi:10.1007/s11412-0099062-z

Boy, G. A. (2013). "From STEM to STEAM: toward a Human-Centred Education, Creativity \& Learning Thinking," in Proceedings of the 31st European conference on cognitive ergonomics, Toulouse, France, 1-7. doi:10.1145/ 2501907.2501934

Buhrmann, T., Di Paolo, E. A., and Barandiaran, X. (2013). A Dynamical Systems Account of Sensorimotor Contingencies. Front. Psychol. 4, 285. doi:10.3389/ fpsyg.2013.00285

Cochrane, T. D., Cook, S., Aiello, S., Christie, D., Sinfield, D., Steagall, M., et al. (2017). A DBR Framework for Designing mobile Virtual Reality Learning Environments. Australas. J. Educ. Technol. 33 (6), 27-40. doi:10.14742/ajet.3613

Cole, M., and Engeström, Y. (2001). "A Cultural-Historical Approach to Distributed Cognition," in Distributed Cognitions: Psychological and Educational Considerations. Editor G. Salomon (Cambridge, NY: Cambridge University Press), 1-46.

Cook, J., and Santos, P. (2016). "Three Phases of mobile Learning State of the Art and Case of mobile Help Seeking Tool for the Health Care Sector," in Mobile Learning Design. Editors D. Churchill, J. Lu, T. K. F. Chiu, and B. Fox (Singapore: Springer), 315-333. doi:10.1007/978-981-10-0027-0_19

Davids, K., Araújo, D., Vilar, L., Renshaw, I., and Pinder, R. A. (2013). An Ecological Dynamics Approach to Skill Acquisition: Implications for Development of talent in Sport. Talent Develop. Excell. 5, 21-34.

Di Paolo, E. A. (2020). Enactive Becoming. Phenom Cogn. Sci. 1, 27. doi:10.1007/ s11097-019-09654-1

Di Paolo, E., Buhrmann, T., and Barandiaran, X. E. (2017). Sensorimotor Life: An Enactive Proposal. Oxford: Oxford University Press.

Díaz-Rojas, D., Soto-Andrade, J., and Videla-Reyes, R. (2021). Enactive Metaphorizing in the Mathematical Experience. Constructivist Foundations 16 (3), 265-274. Available at: https://constructivist.info/16/3/265.

D. Liu, C. Dede, R. Huang, and J. Richards (Editors) (2017). Virtual, Augmented, and Mixed Realities in Education (New York: Springer).

Eames, C., and Aguayo, C. (2020). Designing mobile Learning with Education outside the Classroom to Enhance marine Ecological Literacy. Teach. Learn. Res. Initiat. (Tlri) 28, 20. doi:10.13140/RG.2.2.11865.26728

Emery, S. (2012). Factors for Consideration when Developing a Bring Your Own Device (BYOD) Strategy in Higher Education [online]. Available at: http://hdl. handle.net/1794/12254.

Engeström, Y. (2001). Expansive Learning at Work: Toward an Activity Theoretical Reconceptualization. J. Educ. Work 14 (1), 133-156. doi:10.1080/13639080020028747

Engeström, Y. (1987). Learning by Expanding: An Activity-Theoretical Approach to Developmental Research. Helsinki: Orienta-Konsultit.

English, L. D., and Gainsburg, J. (2016). "Problem Solving in a 21st-century Mathematics Curriculum," in Handbook of International Research in Mathematics Education. Editors L. D. English and D. Kirshner. 3rd ed. (New York: Taylor \& Francis), 313-335.

Frey, C., and Osborne, M. (2013). The Future of Employment: How Susceptible Are Jobs to Computerization? Oxford: University of Oxford.

Froese, T., and Di Paolo, E. A. (2011). The Enactive Approach. PঊC 19 (1), 1-36. doi:10.1075/pc.19.1.01fro

Fuchs, T. (2012). "Chapter 1. The Phenomenology of Body Memory," in Body Memory, Metaphor and Movement. Editors S. C. Koch, T. Fuchs, M. Summa, and C. Muiller (Amsterdam, 9-22. doi:10.1075/aicr.84.03fuc

Fuchs, T. (2018). Ecology of the Brain: The Phenomenology and Biology of the Embodied Mind. Oxford: Oxford University Press. doi:10.1093/med/ 9780199646883.001 .0001

Gallagher, S. (2005). How the Body Shapes the Mind. Oxford: Oxford University Press.

Gallagher, S. (2017). Enactivist Interventions: Rethinking the Mind. Oxford, England: Oxford University Press.

Gibson, J. J. (1979). The Ecological Approach to Visual Perception. Boston: Houghton Lifflin.

Gonzalez-Grandón, X., and Froese, T. (2018). Grounding 4E Cognition in Mexico: Introduction to Special Issue on Spotlight on 4E Cognition Research in Mexico. Adaptive Behav. 26 (5), 189-198. doi:10.1177/1059712318791633 
Hadani, H., and Rood, E. (2018). The Roots of STEM success: Changing Early Learning Experiences to Build Lifelong Thinking Skills. Sausalito, CA: Center for childhood creativity.

Hallowell, R. (2009). Humberto Maturana and Francisco Varela's Contribution to media Ecology: Autopoiesis, the Santiago School of Cognition, and Enactive Cognitive Science. Proc. Media Ecol. Assoc. 10, 144-158.

Hase, S., and Kenyon, C. (2013). Self-determined Learning: Heutagogy in Action. London: A\&C Black.

Heft, H. (2007). The Social Constitution of Perceiver- Environment Reciprocity. Ecol. Psychol. 19 (2), 85-105. doi:10.1080/10407410701331934

Hennessy, S., Mavrikis, M., Girvan, C., Price, S., and Winters, N. (2019). BJET Editorial for the 50th Anniversary Volume in 2019: Looking Back, Reaching Forward. Br. J. Educ. Technol. 50 (1), 5-11. doi:10.1111/bjet.12731

Heras-Escribano, M. (2016). Embracing the Environment: Ecological Answers for Enactive Problems. Constructivist Foundations 11 (2), 309-312.

Heras-Escribano, M. (2019b). Pragmatism, Enactivism, and Ecological Psychology: towards a Unified Approach to post-cognitivism. Synthese 198, 337-363. doi:10.1007/s11229-019-02111-1

Heras-Escribano, M. (2019a). The Philosophy of Affordances. Cham: Palgrave Macmillan. doi:10.1007/978-3-319-98830-6

Honey, M., Pearson, G., and Schweingruber, A. (2014). STEM Integration in K-12 Education: Status, Prospects, and an Agenda for Research. Washington: National Academies Press.

Hurley, M. M. (2001). Reviewing Integrated Science and Mathematics: the Search for Evidence and Definitions from New Perspectives. Sch. Sci. Maths. 101 (5), 259-268. doi:10.1111/j.1949-8594.2001.tb18028.x

Hutto, D. D., Kirchhoff, M. D., and Abrahamson, D. (2015). The Enactive Roots of STEM: Rethinking Educational Design in Mathematics. Educ. Psychol. Rev. 27 (3), 371-389. doi:10.1007/s10648-015-9326-2

Hutto, D. D., and Myin, E. (2013). Radicalizing Enactivism: Basic Minds without Content. Cambridge, MA: MIT Press.

Hutto, D. D., and Sánchez-García, R. (2014). Choking Rectified: Embodied Expertise Beyond Dreyfus. Phenomenol. Cogn. Sci., 1-23. doi:10.1007/ s11097-014-9380-0

Ingold, T. (2000). The Perception Of The Environment: Essays On Livelihood, Dwelling, And Skill. 2nd Edn London: Routledge

Jowsey, S., and Aguayo, C. (2017). O-tū-kapua ('what Clouds See'): A Mixed Reality Experience Bridging Art, Science, Technology in Meaningful Ways. Teach. Curriculum 17 (2), 95-102. doi:10.15663/tandc.v17i2.166

Kelso, J. A., and Fuchs, A. (2016). The Coordination Dynamics of mobile Conjugate Reinforcement. Biol. Cybern 110, 41-53. doi:10.1007/s00422-015-0676-0

Kelley, T. R., and Knowles, J. G. (2016). A Conceptual Framework For Integrated STEM Education. Inter. J STEM Edu. 3, 11. doi:10.1186/s40594-016-0046-z

Krasny, M. E., and Roth, W.-M. (2010). Environmental Education for Social Ecological System Resilience: A Perspective from Activity Theory. Environ. Educ. Res. 16 (5), 545-558. doi:10.1080/13504622.2010.505431

Liao, C. (2016). From Interdisciplinary to Transdisciplinary: An Arts-Integrated Approach to STEAM Education. Art Educ. 69 (6), 44-49. doi:10.1080/ 00043125.2016 .1224873

Lindsay, L. (2015). Transformation of Teacher Practice Using mobile Technology with One-To-One Classes: M-Learning Pedagogical Approaches. Br. J. Educ. Technol. 47 (5), 883-892. doi:10.1111/bjet.12265

Luckin, R., et al. (2010). "Learner-generated Contexts: a Framework to Support the Effective Use of Technology for Learning," in Web 2.0-based e-learning: Applying social informatics for tertiary teaching (Hershey, PA: IGI Global), $70-84$.

Luckin, R. (2008). The Learner Centric Ecology of Resources: A Framework for Using Technology to Scaffold Learning. Comput. Educ. 50 (2), 449-462. doi:10.1016/j.compedu.2007.09.018

Maas, M. J., and Hughes, J. M. (2020). Virtual, Augmented and Mixed Reality in K12 Education: a Review of the Literature. Technol. Pedagogy Educ. 29 (2), 231-249. doi:10.1080/1475939X.2020.1737210

Maass, K. (2007). "Modelling in Class: What Do We Want Students to Learn," in Mathematical Modelling: Education, Engineering and Econom-Ics-ICTMA 12. Editors C. Haines, P. Galbraith, W. Blum, and S. Khan (Chichester, UK: Horwood), 63-78.
Mann, S., Furness, T., Yuan, Y., Iorio, J., and Wang, Z. (2018). All Reality: Virtual, Augmented, Mixed (X), Mediated (X, Y), and Multimediated Reality. arXiv preprint arXiv:1804.08386 2, 14.

Maturana, H., and Pöksen, B. (2010). Del ser al hacer. Los orígenes de la biología del conocer. Buenos Aires: Granica.

Maturana, H., and Varela, F. (1980). Autopoiesis and Cognition: The Realization of the Living. Dordrecht: D. Reidel Publishing Company.

Maturana, H., and y Dávila, X. (2015). El árbol del vivir. Escuela Matríztica, Santiago de Chile: EditoriaL, MvP Editores.

McKenney, S., and Reeves, T. C. (2012). Conducting Educational Design Research. London: Routledge.

Mechsner, F. (2004). A Psychological Approach to Human Voluntary Movement. J. Mot. Behav. 36 (4), 355-370. doi:10.1080/00222895.2004.11007993

Merleau-Ponty, M. (2012). Phenomenology of Perception. Translated by Landes $D A$. New York: Routledge.

Milgram, P., and Kishino, F. (1994). A Taxonomy of Mixed Reality Visual Displays. IEICE Trans. Inf. Syst. 77 (12), 1321.

Miller, E. R., Fairweather, J. S., Slakey, L., Smith, T., and King, T. (2017). Catalyzing Institutional Transformation: Insights from the AAU STEM Initiative. Change Mag. Higher Learn. 49, 36-45. doi:10.1080/00091383.2017.1366810

Milner-Bolotin, M. (2018). Evidence-Based Research in STEM Teacher Education: From Theory to Practice. Front. Educ. 3, 92. doi:10.3389/feduc.2018.00092

Ministry of Education (2016). Bringing the Curriculum Alive: EOTC Guidelines 2016. Wellington: Author.

Myin, E. (2000). Two Sciences of Perception And Visual Ar. J. Conscious. Studies 7 (8-9), 47-59.

O'Regan, J. K., and Noë, A. (2001). A Sensorimotor Account of Vision and Visual Consciousness. Behav. Brain Sci. 24, 939-973. doi:10.1017/S0140525X01000115

Parada, F. J. (2018). Understanding Natural Cognition in Everyday Settings: 3 Pressing Challenges. Front. Hum. Neurosci. 12, 386. doi:10.3389/fnhum.2018.00386

Pellegrino, J., and Hilton, M. (2012). Education for Life and Work: Developing Transferable Knowledge and Skills in the 21st Century. Washington: National Research Council.

Penetito, W. (2009). Place-based Education: Catering for Curriculum, Culture and Community. New Zealand Annu. Rev. Educ. 18 (2008), 5-29. doi:10.1007/9781-4419-0585-7

Philipona, D., and O'Regan, J. K. (2010). "The Sensorimotor Approach in CoSy: The Example of Dimensionality Reduction," in Cognitive Sys- Tems. Editors H. I. Christensen, G. J. M. Kruijff, and J. L. Wyatt (Berlin: Springer), Vol. 8, 95-130. doi:10.1007/978-3-642-11694-0_3

Rietveld, E., Denys, D., and Van Westen, M. (2018). "Ecological-enactive Cognition as Engaging with a Field of Relevant Affordances: the Skilled Intentionality Framework (SIF),," in Oxford Handbook of Cognition: Embodied, Embedded, Enactive and Extended. Editors A. Newen, L. de Bruin, and S. Gallagher (Oxford: Oxford University Press), 41-70.

Rietveld, E., and Kiverstein, J. (2014). A Rich Landscape of Affordances. Ecol. Psychol. 26, 325-352. doi:10.1080/10407413.2014.958035

Roberts, T. (2009). Understanding "Sensorimotor Understanding. Phenomenology Cogn. Sci. 9, 101-111. doi:10.1007/s11097-009-9125-7

Rojas-Líbano, D., and Parada, F. J. (2020). Body-World Coupling, Sensorimotor Mechanisms, and the Ontogeny of Social Cognition. Front. Psychol. 10, 3005-3006. doi:10.3389/fpsyg.2019.03005

Rosch, E. H. (1973). "On the Internal Structure of Perceptual and Semantic Categories," in Cognitive Development and Acquisition of Language (Cambridge: Academic Press), 111-144.

Ryan, K. J., and Gallagher, S. (2020). Between Ecological Psychology and Enactivism: Is There Resonance? Front. Psychol. 11, 1147. doi:10.3389/ fpsyg.2020.01147

Sanders, M. E. (2008). STEM, STEM Education, STEMmania. Technol. Teach. 68 (4), 20-26. doi:10.1080/15710880701875068

Segundo-Ortin, M. (2021). Lectures on Perception: An Ecological Perspective. Philos. Psychol. 34, 318-321. doi:10.1080/09515089.2020.1854710

Shvarts, A., Alberto, R., Bakker, A., and Doorman, M. (2021). Embodied Instrumentation in Learning Mathematics as the Genesis of a Body-Artifact Functional System. Educ. Stud. Math. 107, 447-469. doi:10.1007/s10649-02110053-0 
Siekmann, G., and Korbel, P. (2016). Defining 'STEM' Skills: Review and Synthesis of the Literature-Support Document 1 NCVER. Adelaide, SA, Australia: NCVER.

Smith, J. (2018). Kō Rimurimu 'To Be Covered in Seaweed': Sensory Knowing, Holistic Understand- Ing, and Meaningful Encounters within a Marine Science Centre, Master of Design (MA) Creative Thesis, Auckland University of Technology, Auckland, New Zealand [online]. Available at: http://hdl. handle.net/10292/11734.

Soto-Andrade, J. (2014). "Metaphors in Mathematics Education," in Encyclopedia of Mathematics Education. Editor S. Lerman (Berlin: Springer-Verlag), 447-453. doi:10.1007/978-94-007-4978-8_113

Speicher, M., Hall, B., and Nebeling, M. (2019). "What Is Mixed Reality?," in CHI Conference on Human Factors in Computing Systems Proceedings (CHI 2019), May 4-9, 2019 (New York, NY, USA: Glasgow, Scotland, UK. ACM), 15. doi:10.1145/3290605.330076

Szokolszky, A., Read, C., Palatinus, Z., and Palatinus, K. (2019). Ecological Approaches to Perceptual Learning: Learning to Perceive and Perceiving as Learning. Adapt. Behav. 27, 1-26. doi:10.1177/1059712319854687

The Design-Based Research Collective (2003). Design-based Research: an Emerging Paradigm for Educational Inquiry. Educ. Res. 32 (1), 5-8. doi:10.3102/0013189X032001005

Thompson, E. (2007). Mind in Life: Biology, Phenomenology, and the Sciences of Mind. Cambridge, MA: Harvard University Press.

Turvey, M. T. (1977). "Preliminaries to a Theory of Action with Reference to Vision," in Perceiving, Acting, and Knowing: Toward an Ecological Psychology. Editors R. Shaw and J. Bransford (Erlbaum), 211-265.

Varela, F. (1990). Conocer. Barcelona: Editorial Gedisa.

Varela, F. J. (1999). Ethical Know-How: Action, Wisdom, and Cognition. Palo Alto, CA, USA: Stanford University Press.

Varela, F., Thompson, E., and Rosch, E. (1991). The Embodied Mind: Cognitive Science and Human Experience. Cambridge: MIT Press.

Videla, R., Rossel, S., Bugueño, H., and Urrutia, C. (2021). Diseño e implementación del entorno educativo STEM en estudiantes de tercer año básico: abordaje enactivo y ecológico de la experiencia de aprendizaje. Revista de Estudios y Experiencias en Educación (in press).

Webb, M. E. (2005). Affordances of ICT in Science Learning: Implications for an Integrated Pedagogy. Int. J. Sci. Educ. 27 (6), 705-735. doi:10.1080/09500690500038520

Weisberg, S., and Newcomber, N. (2017). Embodied Cognition and STEM Learning: Overview of a Topical Collection in CR:PI. Cogn. Res. Principles Implications 2, 38. doi:10.1186/s41235-017-0071-6

Wynn, T., and Harris, J. (2012). Toward A Stem 2b+ Arts Curriculum: Creating the Teacher Team. Art Edu. 65, 42-47.

Wenger, E. (1999). Communities of Practice: Learning, Meaning, and Identity. Cambridge: Cambridge University Press.

Yamagata-Lynch, L. C. (2007). Confronting Analytical Dilemmas for Understanding Complex Human Interactions in Design-Based Research from a Cultural-Historical Activity Theory (CHAT) Framework. J. Learn. Sci. 16 (4), 451-484. doi:10.1080/10508400701524777

Conflict of Interest: The authors declare that the research was conducted in the absence of any commercial or financial relationships that could be construed as a potential conflict of interest.

Publisher's Note: All claims expressed in this article are solely those of the authors and do not necessarily represent those of their affiliated organizations, or those of the publisher, the editors and the reviewers. Any product that may be evaluated in this article, or claim that may be made by its manufacturer, is not guaranteed or endorsed by the publisher.

Copyright (c) 2021 Videla, Aguayo and Veloz. This is an open-access article distributed under the terms of the Creative Commons Attribution License (CC $B Y)$. The use, distribution or reproduction in other forums is permitted, provided the original author(s) and the copyright owner(s) are credited and that the original publication in this journal is cited, in accordance with accepted academic practice. No use, distribution or reproduction is permitted which does not comply with these terms. 